\title{
A Concept Analysis of the Properties and Conditions of Transformation
}

\author{
Susan L. Ross \\ Department of Public Health and Recreation, \\ San Jose State University, United States.
}

\begin{abstract}
Transformation is ceaselessly transpiring within and all around us. Despite its pervasive presence, the complex phenomenon remains fundamentally enigmatic. Previous work by this author indicates that existing literature about transformation tends to address its processes, antecedent conditions, catalyst, and/or outcomes. What is lacking is transdisciplinary understanding of the composition of transformation; that which causes transformation to exist. The purpose of this study is to draw upon literature across eleven disciplines to discern properties and conditions integral to transformation. The method selected to achieve this aim is called concept analysis, which constitutes an empirical examination of a phenomenon described in literature, where a concept---transformation in this case---is the research object. The outcomes suggest a classification that indicates transformation is comprised of seven properties with five subproperties, three temporal conditions, and two contextual conditions. These findings constitute a unique contribution to social science research by identifying core aspects of transformation that transcend ethos typically applied in social and natural sciences. Results offer opportunities to further establish a common language so that diverse disciplines can more precisely examine transformation, recognize and apply its processes towards individual and societal growth, and build upon existing theory.
\end{abstract}

Keywords: transformation, initiation, classification, concept analysis, autopoiesis, peak experience

\section{INTRODUCTION}

Transformation as a phenomenon involves processes that are invisible, highly complex, and fundamentally enigmatic. These characteristics hinder our ability to precisely determine what causes an entity to transition from one "form" into another or how the miraculous rearrangement transpires. To add to the complexities, transformation is transdisciplinary and multidimensional (i.e., of matter, psyche, and spirit), effected by and affecting individuals, social and natural systems, and spiritual realms. The outcomes of transformation can escape readily discernable action, as transformation "may or may not manifest in behavior that the individual...is even aware of, let alone observable behavior that researchers can quantify (Coghlan \& Weiler, 2015, p. 14). 
Knowledge of transformation is fragmented because it has mainly been analyzed, described, and defined within discipline-specific contexts thus, collective knowledge is delimited. For example, as studied in adult learning, transformation transpires through learning and causes a dramatic shift in thinking (Mezirow, 1978); in psychology, transformation unfolds through healing and insight producing a new identity (Jung, 1988); in transpersonal psychology, transformation occurs via spiritual breakthrough/breakdown, which expands consciousness (Grof \& Grof, 1989); and systems far from equilibrium can develop order out of chaos rendering a transformation of the system (Prigogine, 1978). Transformation processes and outcomes correlate with the lens through which the information is rendered. A transdisciplinary understanding of transformation that captures commonalities among diverse perspectives is needed. This gap in literature is the inspiration for this and related papers including one that responds to the question "What is the form that transforms as a result of transformation?" (Ross, 2020a) and a second that produces an operational definition of transformation (Ross, 2020b).

The purpose of this investigation is to clarify transformation as a phenomenon by distinguishing properties and conditions salient to its existence and to classify its attributes as an integrated system in order to produce a classification and rich transdisciplinary description that contributes to theory and practice. This research is designed to respond to the question, "What are the essential properties and conditions of transformation?" For the purposes of this study, properties will be defined as fundamental elements that cause transformation as a phenomenon to exist. Conditions will be understood as features of the internal and extremal environment that directly relate to the continuation of transformation.

To accomplish this aim, this study employs a variation of a method called concept analysis (Walker \& Avant, 2010) to examine psychology, physics, anthropology, biological sciences, theology/spirituality, hermetic, nursing, organizational development, mythology, tourism, and transformative learning literature. A concept analysis establishes "attributes of a concept and use[s] words to explain phenomena" with particular attention to extracting subtle aspects (Nuopponen, 2010a; Rodgers \& Knalf, 2000; Walker \& Avant, 2010, p. 25) and "produc[ing] new interpretations about the concept" (Baldwin \& Rose, 2009, p. 782). This asynchronous process is a means through which concepts can evolve progressively and open-endedly, and avoid static certainty (Stevens, 1935).

\section{METHOD}

Used as a research method or an investigation within (or supportive of) a wider study, concept analysis is defined as a type of "inquiry designed to clarify or define a concept by identifying its constituent components and related elements" (Rodgers, Jacelon, \& Knafl, 2018, p. 452). This method requires the use of dictionaries, encyclopedias, and literature to elucidate how the concept is understood in language, history, context, and science-followed by analysis that divides the concept into characteristics and properties, investigates relationships between subconcepts and the core concept, and builds the concept as a system or whole.

Using a modified approach to concept analysis (Nuopponen, 2010b; Rodgers \& Knalf, 2000; Walker \& Avant, 2010) as follows: (a) select a concept; (b) determine the aim and purpose of the analysis, (c) select appropriate sources for data collection; (d) determine defining attributes, relationships, elements, antecedents, and consequences/outcomes; (e) identify and investigate all substitute uses 
and concepts related to the concept; (f) investigate related terms, concepts, and relationships of which literature has not clearly defined; and (g) discuss the meaning and/or application of findings in relevant contexts.

Data collection entailed a comprehensive and methodical review of literature across a wide variety of disciplines with theoretical and empirical contents. I examined literature in psychology, education, nursing, physics, tourism, mythology, anthropology, transpersonal psychology, organizational development, cosmology, and spiritual sources. For inclusion into this study, publications had to respond to the research question, examine transformation as a phenomenon, be inclusive of individual and systems transformation, and scrutinize the antecedents, process, definitions/descriptions, or outcomes/consequences of transformation empirically or theoretically.

As a part of the review, I queried 12 scholarly databases (CINAHL Complete, Nursing and Allied Health Collection, ERIC via Ebsco, PsychINFO, APA, JSTOR, Academic Search Complete, Sage Journals, PubMed, ProQuest, Social Sciences Full Text, and SPORTDiscus with Full Text) using the key words "transformation" or "transform" in the article title. Of these databases, PsychINF0 yielded the highest number of articles $(n=298)$ that, per title and abstract, appeared relevant; each article was reviewed for relevance and hence included or rejected. I also conducted a title search for the words "transformation" or "transform" within the archives of 24 psychology journals. The journals were selected purposively with the intent of capturing perspectives from a variety of countries (United States, Switzerland, Russia/East Europe, Canada, and Britain) and approaches to psychology (clinical, depth, positive, humanistic, evolutionary, individual, applied, theoretical, transpersonal and new ideas). This search yielded 318 articles. I then reviewed the content of all 318 articles to determine relevance and inclusion into this analysis. Of these publications, this paper cites twenty-three.

In addition, I conducted queries of the Internet using a general search using Google and Google Scholar by entering keyword combinations that, per discourse in literature, directly or indirectly pertain to transformation. The key words included "transform," "transformation," "psychology," "systems," "initiation," "rites of passage," "mythology," "hero's journey," "post-traumatic growth," "Dark Night of the Soul," "peak experience," "epiphany," and "transformative learning." All of the above searches yielded thousands of articles that refer to personal transformation and hundreds of articles that note the term in the title-but fewer than 60 contained sentences that define transformation and/or it's characteristics. Of these, 18 publications directly analyzed the phenomenon of transformation in order to scrutinize its nature or characteristics (Bray, 2013; Fosha, 2006; Freedman, 1985; Genmill \& Smith, 1985; Gonzáles, 2004; Hart, 2000; Kottler, 1997; Leffel, 2011; Neal, Lichtenstein, \& Banner, 1999; Persaud, 2000; Prigogine, 1978; Ross, 2017; Scott, 1997, 2003; Taylor, 2012; Wade, 1998; Weiss, 2013; White \& White, 2004).

In order to maximize reliable descriptive and theoretical information, this paper replicated a strategy used in Doyle's (2008) concept analysis where the author identified seminal works about the topic from various perspectives/disciplines. The purpose in this action is to extend the investigation beyond a thorough keyword search and to analyze the content of the most relevant literature with the intent of recognizing seminal leaders and works. In other words, I discovered and included in the investigation, publications that greatly contributed to collective understandingof transformation, as a phenomenon. In total, I found 28 influential publications 
and/or authors dedicated solely to examining and/or comprehending transformation (Almaas, 2000; Ashby, 1956; Aurobindo, 1963/1990; Boyd \& Myers, 1988; Brinton Perera, 1981; Burckhardt, 1960/1997; Campbell, 1968; Dewey, 1964; Eliade, 1958/2005; Grof \& Grof, 1989; Gullahorn \& Gullahorn, 1959; James, 1902/2004; Jung, 1988; Kegan, 1982; Levine, 1976; Mezirow, 1978; Newman, 1978; Ouspensky, 1949/2001; Prigogine, 1978; D.J. Siegel, 2009; I.R. Siegel, 2001; Tedeschi \& Smith, 1995; Tedeschi \& Calhoun 1995; Turner, 1967; Underhill, 1960; van Gennep, 1909/1960; Wiethaus, 1985; Wilber, 1995).

With this collection of sources, I conducted an iterative thematic interpretive analysis as a hermeneutic process that considers the parts and the whole (Takala \& Lämsä, 2001) to elucidate themes in terms of definitions, characteristics, and antecedents (Nuopponen, 2010b). An interpretive analysis "describes the concepts and their use" (Nuopponen, 2010b, p. 13) as does a content analysis, but goes a step further "to find out the reasoning behind the conceptual structures" (p. 13). This approach is a particularly useful way to discover perspectives, relationships, and elements that may contribute to theory development.

As I collected, organized, and documented descriptive terms, concepts, subconcepts, interrelated concepts, processes, and perspectives, I identified those that were not thoroughly described of defined. I conducted secondary and tertiary rounds of investigation of literature until further review of literature yielded similar content and no new information. The purpose of these rounds of analysis is to extinguish any sense of mystery or address a lack of definitive (or a plethora of diverse) interpretation. These iterative processes produced a scaffolding of interrelated properties, subconcepts, and concepts "belonging to a whole" (Nuopponen, 2010a, p. 6) concept system (p. 11), in accordance with this study's purpose.

To make absolutely certain that the literature best reflected "the concept's [true] attributes [i.e., properties in this case] rather than a synonym" (Baldwin \& Rose, 2009, p. 782), I conducted another round of analysis. I analyzed the final themes juxtaposed the definition of form to ensure that indeed, the results did were aligned with the definition of a form.

\section{RESULTS: FUNDAMENTAL PROPERTIES AND CONDITIONS OF TRANSFORMATION}

Findings about each property are described and summarized in the following subsections. Findings from this investigation report three categories of data: properties, temporal conditions, and contextual conditions of transformation. The following sections and subsections vary in length, not because of importance, rather due to complexity. The descriptions of each property and condition report all salient findings. The primary outcomes of this investigation are depicted in Table 1 and constitute a transdisciplinary classification of the properties and conditions of transformation. 
Table1: Properties, Conditions, and Contexts of Transformation

\section{Properties of transformation Meaning or related sub-terms}

Force

Disequilibrium or

creative force

Force producing motion

Impetus of transformation
Dynamism

Non-linear, beyond human control, a dialectic of two (chaos and order) or three forces (active, passive, neutralizing) that undergo fluctuations, disequilibrium, entropy, and symmetry breaking, which is experienced emotionally and/or cognitively as a disorienting dilemma, disorientation, chaos, dissolution, and dismemberment.

Consciousness or divine as a force

Transformative experience as a force

Mind as a force

Grief as a force

Movement

Suspension

Novelty

Irreversibility

Autopoietic

Consciousness defined as a power and substance that consists of discrimination and unity; transcendental, divine, God, miracle, magic, grace, mystery, and ineffable Peak, spiritual emergency, epiphany, perspective transformation, spiritual awakening, boon, crisis, trauma, nadir, mystical experience, catalyst, life-changing experience, catic experience, transformational insight Mind's need to self-reflect, self-analyze, process, and integrate experience and become self-aware Growth producing choices and action, conscious and unconscious

Loss is endemic and throughout the entire transformation process

Outward/upward/beyond, inward/downward, expanding, towards increasing unity, nonlinear

Liminal, limen, anti-structure, threshold, isolation, altered states, interoception, rumination,

Unique contexts and timing, non-proportional phenomenon (butterfly effect), variety, experimentation Permanent change, symmetry breaking, bifurcation, catalyst, non-equilibrium transition, dismemberment, Dark Night, chaos, ego death, crisis, trauma

Re-formation, integration, nucleation, aggregation, or incorporation through self-creating, self-referencing, self-renewing, dialectic, resonance, and/or liminal processes, occurring within an inter/intrapsychic container

Temporal Conditions

A process in linear time that is gradual and/or epochal
Meaning or related sub-terms

Sequential, conversion, enlightenment, epiphany, quantum, catalyst, crisis, shock, jump, chronos and kairos 


\begin{tabular}{|l|l|}
\hline $\begin{array}{l}\text { Non-temporal or outside of } \\
\text { time }\end{array}$ & $\begin{array}{l}\text { State of being, state transformation, kairos, altered state, } \\
\text { presence }\end{array}$ \\
\hline Relevant timing & $\begin{array}{l}\text { Readiness for change, synchronicity, kairos, perfect } \\
\text { timing, and luck }\end{array}$ \\
\hline Contextual Conditions & $\begin{array}{l}\text { Meaning or related sub-terms } \\
\text { Imbalance, chaos, or dissipative structures in the system }\end{array}$ \\
\hline Social disequilibrium & Growth-affirming helper(s) and/or community \\
\hline Psychological support &
\end{tabular}

Note. Copyright Susan Ross, 2019.

\section{Properties of transformation.}

Thematic analysis of the data determined a classification that indicates that transformation has (a) seven salient properties (with five subproperties), (b) three temporal conditions, and (c) two contextual conditions. The following is a rich description of each.

\section{Dynamism}

A personal transformation is explicitly defined as being dynamic (Freedman, 1985; Mezirow, Taylor, \& Associates, 2009; Scott, 2003; Tedeschi, Calhoun, \& Groleau, 2015; Wade, 1998). Dynamic as an adjective is defined as "a process or system characterized by constant change, activity, or progress" (Dynamic, 2019, def. 1), and as a noun, "a force that stimulates change or progress within a system or process" (def. 1). The field of physics states that dynamism "relat[es] to forces producing motion" (def. 1.1), while in philosophy, dynamism is "a theory that phenomena of matter or mind are due to the action of forces rather than to motion or matter" (Dynamism, 2019, def. 2). Dynamism derives from the Greek word dunamis (power), which may be the result of combining force and motion together (Dynamism, 2019, “Origin"). Dynamism constitutes the fundamental nature of transformation and appears to be the source, animate, and encompasses all other properties.

\section{Force}

Force is the first aspect of dynamism. This study reports five phenomena that produce force during transformation: disequilibrium/creative, consciousness/divine, transformative experience, mind, and grief. The following is a synopsis of each finding.

Disequilibrium or disorder are forces that cause new entities to be created. Moreover, the Nobel prize-winning theory of nonunitary transformation (Prigogine, 1977/1993) explains how matter transforms through irreversible processes into a more complex structure called a dissipative structure. The system enters transformation when "internal or external conditions of a system are...turbulent enough to push it out of the limited parameters where it was able to maintain equilibrium" (Genmill \& Smith, 1985, p. 753). This theory suggests that the force of transformation is disorder or chaos, which causes a system to reorganize into increased complexity and sophistication. Chaos catalyzes transformation through processes referred to as "order through fluctuations" (Gilstrap, 2007, p 53)-“system jolts, turbulent environmental conditions, or internal conflicts" (Genmill \& Smith, 1985, p. 752), As applied within social (Loye \& Eisler, 1987) and biological sciences (Newman, 1978), this theory shows how the force of fluctuations (i.e., the psychological disruption, challenge, crisis, or peak) causes the structure (i.e., ego, identity, mind, or body) to move through a temporarily chaotic condition to a "nonequilibrium phase transition" 
(Prigogine, 1978, p. 782), and then to a new higher order (Genmill \& Smith, 1985). These instigating forces cause transformation to have a nonlinear characteristic: "unreachable" (Neal et al., 1999, p. 179), beyond "linear logic" (Lichtenstein, 1997, p. 403), or even transcendent, because the processes exist beyond rational prediction and control. This scientific breakthrough demonstrates that "dissipative self-organizing process is the driving force behind the evolution of all systems" (Genmill \& Smith, 1985, p. 754).

Application of Prigogine's theory to human transformation (individual and systems) suggests that the necessary chaos provokes intense emotional discord. Because transformation "can only take place after a state of disequilibrium has unleashed dynamic forces [italics added]" (Freedman, 1985, p. 323), a period of psychic dissonance (i.e., profound emotional distress or despair, significant emotional crisis, or spiritual/identity loss) is a force that precedes a breakthrough to a new order (Baker, 2012; Clark, 1958; Gonzáles, 2010; James, 1902/2004; Levitt et al., 2004; Loder, 1989; McDonald, 207; Mezirow, 1978; Miller, 2004; Neal et al., 1999; Ross, 2017; Scott, 1997; Starbuck, 1901; Taylor, 2012; Weiss, 2013; White \& White, 2004). Psychological disequilibrium is an "aversive, motivating state that leads to adaptation" (J. T. Siegel, 2013) that can lead to a nadir experience (Thorne, 1963-one of the lowest points of one's life-that renders feelings of powerlessness (James, 1902/1997), emptiness (Almaas, 1986/2000); a sterile void (Perls, 1959/1969), "void of uncertainty" (Genmill \& Smith, 1985, p. 762), dismemberment (Brinton Perera, 1981; Churchill, 2011; Ross, 2017; Woodman, 1985) existential vacuum (Frankl, 1946), "suffering of opposites" (Trousdell, 2008, p. 9), or entropy (Prigogine, 1978). Although the emotional strife of disequilibrium and chaos is agonizing, the experiences are "necessary conditions for transformation" (Scott, 2003, p. 280; also see Lindstrom, 2011; Ross, 2017) and paradoxically, the crisis is the "source of order" (Prigogine, 1977/1993, p. 284), where "the fire of the heart" is a force or active agent (Jung, 1955/1970, p. 46).

A creative force can be interpreted as the universal force causing the dissipative structure to enter into flocculation and chaos, when discussed in psychospiritual terms. One perspective states, "the activity of creation....produces new forms," which is a "pulse that drives self-organization and selftranscendence" (Hart, 2000, p. 157). From this primordial view, there are two dialectic and fundamental forces of creation, recognized as yin and yang in Eastern traditions, King and Queen in the Kabbalistic system, and Ishwara and Shakti in Hinduism. In hermetic sciences or alchemy, the forces are symbolized by Sulphur and quicksilver, "the force that forms and moves the worlds" (Aurobindo, 1963/1990, p. 139). While the "dynamic interplay between these opposites" produces the energy needed for the personal growth and emotional surrender transformation requires (Hart, 2000 , p. 158), other philosophies suggest that all new creations derive from the union of not two but three forces: active, passive, and neutralizing (Ouspensky, 1949/2001); thesis, antithesis, and synthesis (Freedman, 1985); or attraction, repulsion, and circulation (Atwood, 1960/1850, p. 153).

Consciousness or divinity appears to be a force-producing motion. Described by Indian teacher and author Sri Aurobindo, consciousness is a "force-substance" (Aurobindo, The Mother, \& Dalal, 2002, p. 15) that has capacities of discrimination (ability to break down) and unity (ability to integrate). In his theory of evolution, Aurobindo (1963/1990) states that the ultimate desire of God is to descend as consciousness into matter through a process called involution and then emerge out of matter in a process of evolution, causing all matter to rise in conscious awareness of itself. The goal of the movement is for matter (i.e., including human beings) to have complete self-awareness, 
integrally containing a dynamic tension that is aware of its self as separate from and in union with all, bound to earthliness and transcendent (for more, also see Ross, 2019).

According to hermetic science, "Ancient and spiritual epitaphs propose that transformation requires divine aid...[where the goal] is obtained not by the might of man, but by the grace of god" (Olsen, 1992, p. 74); humans "can do nothing but sow, plant, and water: God must give the increase" (p. 36). Sri Aurobindo states, "if no wider and higher truth intervenes [the person with be left with] old confusion in a new form" (Aurobindo et al., 2002, p. 170). Although individuals can contribute to transformation by being open to and calling upon larger powers, "a descent of the Divine Nature can alone divinize the human receptacle" (Aurobindo, 1972, p. 71). Gurdieff concurs, "without outside help a man can never see himself" (as cited in Ouspensky, 1949/2001, p. 149) but warns that it is inaccurate to interpret a mysterious phenomenon as a miracle-from God. He purports that unexplainable fortune or synchronicities can be understandable when viewed from a different paradigm; "a miracle is not a breaking of laws, nor is it a phenomenon outside laws...[it is] the manifestation of the laws of one cosmos in another cosmos" (as cited in Ouspensky, 1949/2001, p. 207).

A transformative experience (i.e., a life-changing peak or trauma) is also a force that causes "motion by intensely affective experiences" (Tedeschi et al., 2015, p. 559; see also Neal et al., 1999) such as a peak (Maslow, 1999), spiritual awakening (Assagioli, 1975) or dehypnotization (Ouspensky, 1949/2001), realization of wisdom (Turner, 1969; van Gennep, 1909/1960; White \& White, 2004) such as boon (Campbell, 1968), transformational insight (Levitt et al., 2004), cathartic experience (Zahra \& McIntosh, 2007), ecstasy (Churchill, 2011), or personal crisis (Miller, 2004; White \& White, 2004). One qualitative study of 55 informants said the transformative experience has "distinctiveness," meaning "something out of the ordinary," surprise, and benevolence (Miller, 2004, p. 455). Although the experiencer may feel as though or believe they have transformed, data suggests that having a transformative experience does not equate to the permanent change necessary for transformation (Chandler, Holden, \& Kolander, 1992; Grof \& Grof, 1989; Hoffman, 2012; Robledo \& Batle, 2015; Ross, 2017).

Mind is another force affecting transformation because transformation often involves epiphanies (functions of the mind) and requires critical engagement, reflection, planning, ruminating, and many other cognitive processes (Aurobindo, 1972; Jung, 1988; Mezirow, 1978; Tedeschi \& Calhoun, 1995; Wade, 1998). Daniel Siegel (2017) suggests the force of transformation stems from "the fundamental push of the mind [italics added] to integrate...our sense of past, present, and future" (p. 85). Transformative learning theory (Mezirow, 1991, 1997, 2000) posits that the force producing motion is a disorienting dilemma, a pressing problem for which there is no clear solution (Mezirow, 1978, p. 101). Akin to a "dialectic conflict" in psychiatry (Freedman, 1985, p. 319) or "seismic event" (Tedeschi \& Calhoun, 1995) in post-traumatic growth work, a disorienting dilemma can be described as "the need to overcome the disbelief caused by having foundational premises shaken, forcing the realization that the world can no longer be as it had seemed" (Levitt et al., 2004, p. 20). The learner reconciles the existential crisis by critically examining long-held beliefs and ideas about their underlying assumptions, expectations, worldviews, and cultural paradigms, resulting in what Mezirow (1978) calls a perspective transformation. A similar psychological term, metanoia, a change of one's mind-turning around-towards the self (Petruska, 1989) reflects this phenomenon. From 
a psychological perspective, the act of embracing the dilemma (as opposed to rejecting it) is a central force propelling transformation forward (Taylor, 2012).

Following a life-changing trauma, the activities of ruminating or cognitive processing, maintaining positive emotions, self-disclosing, and restructuring one's personal narrative contribute to the psychological stabilization and growth needed for transformation (Ross, 2017; Tedeschi \& Calhoun, 1995). The initiate must "commit, submit and embrace the journey" (Bray, 2017, p. 6) to learn, grow, and heal by making choices and taking actions that are life-giving and healthier than those of one's past (Aurobindo, 1972; Campbell, 1968; Grof \& Grof, 1989; Jung, 1934/1988; Lindstrom, 2011; Ross, 2008; Taylor, 2012; Tedeschi et al., 2015).

Grief may be a force-producing motion during transformation (Boyd \& Myers, 1988; Fosha, 2006; Scott, 2003), and especially potent during integration processes (Ross, 2017). Grief is "a critical condition for the possibility of personal transformation" (Boyd \& Myers, 1988, p. 280) because it enables release of outdated behavioral patterns, which facilitates "restabilization and reintegration [italics added]" (Boyd \& Myers, 1988, p. 279) and results in a fuller sense of one's self. For example, during a disorienting dilemma the individual is "forced" to confront a new reality or world view. As the individual accepts the new perspective as ontologically valid, he or she experiences loss for what had been real or true, and grieves the losses. These deep feelings of loss cause "an involuntary disruption of order...[becoming] the vehicle [or] transporting process" of transformation (Boyd \& Myers, 1988, p. 278).

In summary, transformation is essentially dynamic, which connotes that transformation is propelled by a force that influences motion. The literature suggests that the force causing transformative movement is the same force responsible for creation within the universe, consisting of a tension between opposites or the dynamic between three: active, passive, and neutralizing. At an individual level, the force produces transformative experience(s), disequilibrium, crisis, epiphany (i.e., insight or alteration of worldview), and grief, all of which propel processes toward re-formation.

\section{Movement}

The second half of dynamism - a force producing motion-is movement. The prefix trans-postulates some ideas about the direction or quality of the movement; it is defined as "across, to or on the farther side of, beyond, [or] over" (Trans-, 2019, def. 1) and "from one place person, thing or state to another" denoting moving beyond, surpassing, and transcending (def. 2.2). When combined, transform indicates outwardly movement, going beyond form. Transformation is typically described as a process, and "process can be defined [during transformation] as the movement, the flow...toward wholeness" (Wiedemann, 1985, p. 2).

Movement is identified as a primary characteristic of health (de Grâce, 1974), life itself (Clements, 2016, p. 69), and personal transformation processes (Baker, 2012). Life itself can be viewed as constituting two central modes of movement: outward (expansion) or inward (retraction; Reich, 1949), ascending (evolutionary) or descending (creative; see Aurobindo, 1963/1990; Murdock, 1990; Ouspensky, 1949/2001, p. 134) or both directions (Ross, 2017). Findings from Ross' research suggest that during transformation, the psyche moves in the pattern of a figure-eight. The movement "begins" at the center of the eight, moves upwards/outwards beyond (i.e., trans-) the self 
into the cosmos (counter-clockwise) constituting a transformative round, then downwards/inwards into the self/earth/underworld (clockwise) comprising an integrative round, and returns back to the center, establishing a never-ending cycling (2020c).

The sciences of transpersonal psychology (Baker, 2012; Grof \& Grof, 1989), religious (Leffel, 2011), physics (Prigogine, Nicolis, \& Babloyantz, 1972), hermetic (Burckhardt, 1960/1997), transformative learning (Boyd, 1990), and nursing (Newman, 1972) identify that consciousness or awareness expands or opens up (Hart, 2000, p. 157) during transformative (i.e., life-changing peak or trauma) processes. Sciences of depth psychology (Brinton Perera, 1981; Lincoln, 1981; Woodman, 1985), transpersonal psychology (Almaas, 2000), religion/spirituality (Aurobindo, 1963/1990) and transformative studies (Ross, 2017) identify that consciousness or awareness contracts or moves inward during integrative phases of transformation. One study deciphered that consciousness moves "beyond [emphasis added] identification with the form of the socially constructed identity and toward realization of the essential self" (Baker, 2012, p. iii). From the perspective of mysticism, the direction of a transformation in consciousness is toward the divine (Danielou, 1964). Transformation as studied in anthropological analysis of rites of passage identifies the centrality of geographical movement to the success of the initiation (i.e., transformation) (Turner, 1969; Turner, 1978; van Gennep, 1909/1960).

Physics (Prigogine, 1978), chaos theory (Prigogine \& Stengers, 1984) hermetic science (Burckhardt, 1960/1997), and systems theories (Ashby, 1956) indicate that the movement of transformation is nonlinear, especially when the individual is psychologically far from equilibrium and "therefore highly sensitive to certain influences" (Lichtenstein, 1997, p. 405). These theories suggest that during periods of chaos and fluctuation, even a small but critical movement can cause disproportionately massive change or systemwide transformation-the butterfly effect or nonproportional phenomenon (Lichtenstein, 1997, p. 406).

During transformation, the entity moves internally as it reorganizes into increased unity and internal diversity (Aurobindo, 1963/1990; Freedman, 1985), shifting "from fragmentation towards wholeness [and] from separation to connection" (Baker, 2012, p. iii). Newly created internal structures of the ego, mind, or body (Ross, 2020a) are refined and "reveal more of what actually exists" (Hart, 2000, p. 157), enable self-actualization (Maslow, 1999), and help individuals become "more uniquely who [they] are" (Hart, 2000, p. 157).

To summarize, transformation (i.e., transformative and integrative cycles) causes the individual's consciousness to move upward and/or outward, beyond the entity's previous identity and later, inward and/or downward to release and integrate the true self. The individual reconfigues within towards greater unity, diversity, and order to reveal more clearly its essence, "the thing as it is in itself" (Persaud, 2000, p. 42).

\section{Suspension}

In a lecture series, Carl Jung (1934/1988) translated the work of German philosopher Friedrich Nietzsche when he specified, "suspension...is the state of transformation" (p. 187). Jung refers here to periods when a person amid the process of personal transformation resides in a psychologically ambiguous, altered state, accentuated by considerable interludes of introspection, stillness, 
solitude, and silence that are directly linked to a successful transformation (Assagioli, 1975; Sinetar, 1986; Lindstrom, 2011; Luke, 1984, Persaud, 2000; Ross, 2017).

Suspension is most thoroughly described by anthropology as liminality, which is central to transformation during a rite of passage. Described as a threshold, the liminal phase stimulates an altered state, which is

any mental state, induced by various physiological, psychological, or pharmacological maneuvers or agents, which can be recognized subjectively by the individual...as representing a sufficient deviation in subjective experience or psychological functioning from certain general norms for that individual during alert, waking consciousness. (Ludwig, 1969, pp. 9-10)

Liminality is both literal and psychic, causing the initiate to be between worlds, having left the previous one and not yet arrived at the new. In a psychic sense, the initiate or "passenger" (Turner, 1967, p. 94) is said to be "invisible" (p. 95), "betwixt and between" (p. 93), a "transitional-being" (p. 95). Liminality includes antistructure, becoming freed from socioeconomic pressures, behavioral norms, and hierarchical structures that give order to daily living. In this freed state, known rules of conduct may or may not apply (Turner, 1969; Turner, 1978; van Gennep, 1909/1960), and the novel environments cause the initiand to be open to possibilities "which lie at the edge of cultural norm...temporarily restructuring consciousness" (Tart, 1986, p. 4). An empirical analysis of liminal experience among people volunteering internationally concluded that liminality "is not necessarily due to the projects [with which the volunteers engage]...but rather due to placelessness and timelessness" sensed by the volunteers (Mustonen, 2005, p. 172). A different study confirmed that "isolation-induced introspection" is a precondition for the transformative peak (White \& White, 2004, p. 464).

Suspension makes possible indwelling or interoception (perception of bodily sensations), which is vital to transformation because "Our body becomes the vessel for an incarnation of which we become one with and this occurs in [in particular, during] the suffering and suspension aspects of transformation" (Jung, 1934/1988, p. 200). This property allows the initiate to endure "traumatic discontent" (White \& White, 2004, p. 466), the "torment in order to embody or incarnate the unconscious contents" (Jung, 1934/1988, p. 194) by "facing inner depths which appear dark" (Aurobindo, 1963/1990, p. 122) during dismemberment, when ego death occurs and in surrender and healing, when past wounds are reconciled (Ross, 2017). This aspect of transformation requires excessive hours of stillness, rest, and quiet at home in solitude (Ross, 2017; also see Gunn, 2000) where the individual craves "being submerged in...unconscious energies" (Downton, 1989, p. 76). Inward emotional engagement in "subtle and slow" integration processes coincides with rumination aspects of post-traumatic growth (Tedeschi et al., 2015). Jung (1934/1988) advises, "Either one dies in that suspension, producing the subtle body through death, or one produces superior knowledge" (p. 187). Aurobindo (1963/1990) contends the risk is advisable; "entry into this obscurity, this void, this silence is only the passage to a greater existence” (p. 122).

To summarize, the state of transformation mandates an element of psychospiritual and even social suspension, where the individual has a sense of being in transition, in an altered state, and internally 
absorbed. Suspension allows the dissolution, rearrangement, and re-building necessary to transformation.

\section{Novelty}

Novelty is a critical antecedent to the catalytic or transformative aspect of transformation (Coghlan \& Weiler, 2015; Genmill \& Smith, 1985; Henderson, 1995; Kottler, 1998; Lean, 2009; Levitt et al., 2004) and pertains to an experience that is new or unfamiliar (Novelty, 2019, def. 1.1). During traditional rites of passage, elders bring the initiate to novel locations at the edge of or beyond territorial boundaries that demand thinking and acting in ways unfamiliar to the individual (Moore, 2001; V. Turner, 1969; White \& White, 2004). An examination of transformative travel of 61 people residing in 17 countries reported "being away from [a] familiar setting as one of the primary reasons for their transformation” (Lean, 2009, p. 199).

Novelty also comes in the form of timing, in that the individual will respond differently to any given event based on when, where, and with whom the occasion transpires. For example, important events can be judged as luck or misfortune, a miracle or a tragedy, or a synchronicity based on timing and circumstances. Carl Jung (1969/2011) describes a synchronicity as "a meaningful coincidence of two or more events, where something other than the probability of chance is involved" (p. 520). Regardless of how novelty is labeled, the concept of transformation includes a novel intersection between the experiencer, the experience (which includes the place), and their location in time (Ross, 2010), which might cause a person to say, "I have not ever had an experience like this before." This property overlaps with the temporal condition discussed below called "relevant timing".

In reference to systems theory, psychiatrist and pioneer of cybernetics W. Ross Ashby (1956) studied transformation of complex systems and devised the Law of Requisite Variety. This theory highlighted that "variety within a system is critical for its survival" (Gilstrap, 2007, p. 55). Additionally, systems theory and physics identify that "novelty or variation will ultimately be the system's best tool for dealing with a highly variable and uncertain environment" (Genmill \& Smith, 1985 , p. 755). In particular, a process called experimentation within a system must "reproduce what appear to be errors, that allows the system to generate a sufficient variety of new forms" so that a novel configuration of errors might "become a new preferred configuration around which the system can reorganize" (Genmill \& Smith, 1985, p. 755). In other words, willingness to experiment without judgement produces more opportunities for novel configurations-and therefore, transformation.

To conclude, novelty involves exposure to newness of thinking, acting, and sensing, which may include being in physically unfamiliar places. Novel experiences cause the entity to become open to receiving new information and to experiment with possibilities, actions integral to transformation.

\section{Irreversible}

Permanent or irreversible change is a hallmark of transformation because a change "is not truly a transformation unless it is sustained through time" (Gilmore \& Pine, 2011, p. 286). The lasting changes must constitute "attitude, performance, characteristics, or some other fundamental dimension of the self...not only in...function but also in structure" or "no transformation occurs" (Gilmore \& Pine, 2011, p. 254). 
Literature suggests that irreversibility results from dissolution of the outdated structure, a process identified in psychology as ego death (Jung, 1934/1988), the Dark Night (i.e., St. John of the Cross), dismemberment (Brinton Perera, 1981; Ross, 2017; Woodman, 1985), and spiritual emergency (Grof \& Grof, 1989), and physics as chaos (Prigogine, 1977/1993) or symmetry breaking (Genmill \& Smith, 1985). The term "symmetry breaking," as derived from physics, is how "nature achieves its most delicate and complex structures" (Prigogine, 1997, p. 26). When applied in systems theory, the term implies "breaking down of existing functional relationships, patterns of interactions or systems habits that have previously been the source of equilibrium" (Genmill \& Smith, 1985, p. 755), which "makes transformation a reality" (p. 762). In other words, an irreversible change in the form or structure of a thing occurs when its symmetry is broken. In hermetic sciences, dissolution is viewed as purification and is referred to as "spagyric medicine" (Burckhardt, 1960/1997, p. 20), derived from a Greek word meaning "divide and unite" (terms also described earlier as the essential nature of consciousness). The structure dissolves and coagulates, causing the union of opposites within the individual. These polar dynamics that exhibit characterisitics of consciousness may give further insight into why one study found that consciousness emerges from the form that is transformed during transformation (Ross, 2020a).

To summarize, transformation creates a marked, irreversible, permanent change in the form of a thing by dissolving the outdated structure and then unifying the entity into a novel and more complex configuration. This process fundamental alters the function and structure of the entity.

\section{Autopoietic}

Transformation is autopoietic, a Greek adjective comprised of auto, meaning self, and poietic, "capable of making, creative, productive"; together, the term connotates self-creating (Autopoietic, Online Etymology Dictionary). The term was introduced by biologists Humberto Maturana and Francisco Varela in 1973 "to name the self-producing organization that is unique to living things" (Bouissac, 2007, para 1). The autopoietic properties cause "intentional movement towards greater openness to change" that involves experimenting with all potential configurations, self-organizing, and rebuilding the form or structure into a new whole (Genmill \& Smith, 1985, p. 756). Autopoietic activity in psychological language happens through dissolution of the ego (Jung, 1988), spiritual emergency (Grof \& Grof, 1989), or dismemberment (Ross, 2017) and when wounds are mended and reconciled (i.e., surrender and healing phase; see Ross, 2017).

A coinciding concept used in depth psychology is a dialectic; it refers to "the process of creating new syntheses" through relatedness between the self and one's unconscious and the self and clinician (Jung, 1935/1966a, p. 17). A dialectic involves integrating inner contradictions; the "ability [to] simply look at what is terrifying in order to establish a relationship with it....[to] suffer what she sees" (Trousdell, 2008, p. 29) These transformational processes require intrapsychic containment, via the "self as the container and organizer of all opposites" (Jung, 1946/1966b, p. 412) and through "the matrix, the hollow form, the vessel...of consciousness" or "the mother" (p. 222).

During autopoiesis, "resonance.....among system parts, acts as a bonding element upon which....accelerated....change can build" [emphasis added] (CITE; pp. 756-757; also see László, 1978), which is "crucial for reformulation around a new configuration" (p. 757). Structure building of autopoiesis is facilitated through a "nucleation mechanism" (Prigogine \& Stengers, 1984, p. 189). 
Nucleation is a term used in chemistry to depict how crystals form when "a small number of ions atoms, or molecules become arranged in a pattern characteristic of a crystalline solid, forming a site upon which additional particles are deposited as the crystal grows" (Encyclopedia Britannica, nucleation). The initial nucleation "determines many properties of the emerging" structure (Vekilov, 2010, p. 5007). Similar to physics, psychological structure building relies upon an "imprint of habits from the past" (O'Sullivan, 1999, p. 210) to re-create itself such that the new structure is in-formed by history.

Autopoiesis and nucleation processes indicate that biopsychospiritual reconfiguration during transformation begins with internal resonance and derives from processes responsible for organizing the basic structures of life. Nucleation equates to human transformation processes occurring after dissolution of the outdated structure such as the ego (i.e., ego death), when an archetype or the unconscious manifests "as a reconciling symbol...that points the way forward...[and] maps out the hard work of transformation" (Trousdell, 2008, p. 9). The symbol or image represents the individual's goal and "unites the opposites...by combining them in the form of a cross....[or] the idea of wholeness through the circle or sphere" (Jung, 1946/1966b, p. 319). Philosopher Gurdjieff similarly states, "When a permanent center of gravity has been created everything else begins to be disposed and distributed in subordination to it" (Ouspensky, 1949/2001, p. 259). Psychic containment and dialectic relationship may give rise to internal resonance that builds as opposites are reconciled, which in turn results in "wholeness that resolves all opposition" (Jung, 1946/1966b, p. 289), "embodied human experience" (Troudsdell, 2008, p. 25), and transformation.

In all, the property of autopoiesis is what guides processes of intellgent re-design that is endemic to transformation. Autopoiesis causes the structure to dissolve, its most essential elements to selforganize in a new pattern, rebuild and re-create a new structure based on that fundamental pattern, which results in a transformed whole. Autopoiesis is integral to all life and places the most basic elements of an entity, at a nuclear level, into greater order.

\section{Temporal conditions}

Direct analyses of transformation reference time or timing of events as central to the existence of transformation (Hart, 2000; James, 1902/2004; Pikovsky, Rosenblum, \& Kurths, 2001). In particular, time is a primary reference used to observe change and/or experience, evidenced by verbalizations such as "It happened in an instant" or "It took three years until I started to feel like myself again" or "The realization occurred just as I stepped onto stage". The following is a description of three subthemes pertaining to time and transformation: linear time, nontemporal, and relevant timing. 


\section{Linear time}

Transformation is depicted as occurring in an instant of conversion, enlightenment, mystical experience (Chilton, 2015; James, 1902/2004; McDonald, 2007; Steiner, 1904-1905/2005), quantum change (Miller, 2004), jump (Tart, 1986, p. 7), or shock (Ouspensky, 1949/2001, p. 192); or as a process (Kioukova, 2016; Metzner, 1998; Saunders, Laying, \& Weiler, 2013; Scott, 2003; Snyder, 2008; Wade, 1998) that is either epochal (i.e., quickly) or gradual (Mezirow, 1991, 2000); or "rapidly and gradually, dramatically or subtly" (Anderson \& Braud, 2011, p. xvii). Although transformative life-changing events give the impression that transformation happens rapidly, the pivotal experience is just one part of a larger gradual and subtle process that can extend for years (Ross, 2020c). Mystic George Gurdjieff states, "It is impossible to awaken completely all at once" (as cited in Ouspensky, 1949/2001, p. 219) and the scholar Eliade (1958/2005) agrees, "genuine and definitive conversions are comparatively rare in modern societies" (p. 135). In order to transform, "one must first begin to awaken for short moments" (Ouspensky, 1949/2001, p. 219) and bring the "treasure of understanding back and [to] integrate it in a rational life" (Campbell, 2004, p. 119).

\section{Nontemporal}

Transformation as a nontemporal process is a state of being or mind, which implies immersion in the present moment; therefore, "transformation involves freedom from time and space" (Hart, 2000, p. 162). Transformation as a state is "more than just continuous re-formation or progressive change-it is a permanent state of becoming and unbecoming, much of which is unconscious, contradictory" (Schmidt-Lauff, 2012, p. 111). Nontemporal conditions assume presence and internal focus, where the individual becomes "free from spatial limitations or from fixity of perspective," thus altering the ways in which the individual gazes upon and interprets inner and outer experience (Hart, 2000, p. 162). In the context of a psychotherapeutic relationship, psychological transference can be a relational, interactive, mutually affecting "transformative field" (Hall, 1984, p. 31) that follows quantum rather than Newtonian law (Mansfield \& Spiegelman, 1996). One theorist clinician says that the transformative field places individuals in "direct contact with the transcendent" (Ulanov, 1997, p. 119).

One study reported that a transformative field emerged through a cooperative inquiry due to shared intentions, centrality of the sacred to all activities, commitment to transform, and "attentiveness as a moment-to-moment metaphoric, archetypal, synchronistic" circumstances (Ross, Zammit, \& Zollinger, 2005, p. 409). Conversely, anthropologist Victor Turner (1967) makes explicit that transformation during rites of passage is a transition, not a state. According to chaos theory, if a phenomenon can be identified from a single observation, then the entity is in a state, not a process (Pikovsky, Rosenblum, \& Kurths, 2001, p. 17). Although the majority of the literature and research identifies transformation as occurring in linear time, I suggest that transformation as a state-ofbeing is plausible. I conclude that transformation can be a nontemporal and/or sequential/epochal phenomenon, depending upon the experiencer's perspective.

\section{Relevant timing}

Key events during transformation have specialized and personally relevant timing described as synchronistic (Jung, 1988; Ross, 2017) or kairos, a Greek word that indicates a window of opportunity beyond linear time and particularly related to one's destiny (Gonzáles, 2010; Kinneavy \& Eskin, 2000). The "right timing" for synchronistic, pivotal, or life-changing events during transformation is related to the individual's "readiness for change" (Frick, 1987, p. 421) including 
emotional and egoic strength and self-reflexive skills (Fosha, 2006; Jung 1968; Ross, 2008; Tedeschi et al., 2015; Wilber, 1996), all of which may be achieved unconsciously (Grof \& Grof, 1989). Readiness for opportunities is also evidenced by the ability to make use of unfamiliar information, sensations, and/or consciousness (Wilber, 1996). These psychological "stabilities...assist in the reformulation process" (Genmill \& Smith, 1985, p. 754).

In review of this subsection, transformation has temporal properties because time is the medium through which change can be observed. Transformation is an incremental process occurring in linear time with epochal transformative events and altered states; however, it is also be nontemporal, as an ongoing immersive relational state of engagement with a "transformative field" (Hall, 1984). Finally, the process as a whole, including pivotal events during transformation-such as an epiphany-have a timing that is personally relevant or indicative of readiness for change.

\section{Contextual conditions}

Transformation of the individual and collective are inseparable and interdependent (Bohm, 1983; Hart, 2000). In this analysis, transformation is simultaneously a sociocultural and individual process that affects the initiate and society (Tedeschi, 1999; Turner \& Turner, 1978).

\section{Context of social disequilibrium}

Social disequilibrium and personal transformation are mutually reinforcing. Problems existing within environmental, social, economic, historical, political, media, religious, educational, and familial conditions affect system-wide disequilibrium, which eventually prompts societal transformation (Neal et al., 1999). The term disequilibrium, as used in the natural sciences, is a system out of balance. Systems theory purports "the most profound changes in society, the changes that have had a lasting effect, come via whole system change rather than through step-by-step processes" (Genmill \& Smith, 1985, p. 752). Furthermore, the system's change involves a "reformulation of system parts and a total alteration [italics added] of forms, relationships, and the processes of maintenance and growth" (Genmill \& Smith, 1985, p. 752). The "core benefits" of system transformation are "non-material...even spiritual" (Neal et al., 1999, p. 176).

Disequilibrium in the system can cause people within the system to feel "out of the control" (Neal et al., 1999, p. 179), contributing to personal transformation processes. Personal transformation in turn, directly affects, ends, or initiates close relationships (Ross, 2008), which in turn, affects the larger social system. According to transformative learning theorist Robert Boyd (1990), there are five ways that a social system can affect personal transformation: (a) primary relationships and emotions are influenced by primordial and archetypal patterns present in a group; (b) group development issues require the individual to address those same issues internally; (c) group structures develop skills and experiences of "experimentation, exploration, and disclosure" ( $p$. 525); (d) diversity offers psychological projection and potential for insight, and (e) vicarious experience through sharing offered by the other provides opportunities for self-awareness.

\section{Context of psychosocial support}

Personal transformation requires psychosocial support from at least one trusted other and ideally, from an encouraging and growth-affirming community that espouses a sense of safety, love, selfreflection, cognitive processing, and narratives about self and other portraying growth (Baker, 2012; Boyd \& Myers, 1988; Ross, 2008; Tedeschi et al., 2015; White \& White, 2004). Analysis of a 
transpersonal psychology program reported that students the relational community served as a "vessel offering the right tools [about how to gain self-awareness]...and right conditions [love]" to support the individual's transmutation (Baker, 2012, p. iii). Lack of interpersonal support, on the other hand, could cause transformation to be aborted (Bray, 2017; Ross, 2010).

A traditional initiation ritual is conducted within the community's active engagement-mentally, emotionally, physically, and spiritually-and as such, the community is not psychically separate from the initiand (Brinton Perera, 1981; Maddern, 1990; van Gennep, 1909/1960; Turner, 1969; Woodman, 1985). Because the community functions as a whole, all members experience change, and the rite of passage regenerates the entire community (Eliade, 1958/1994) or beyond (Tedeschi, 1999). Another purpose of a transformation via initiation is to "teach the lesson of the essential oneness of the individual and the group" (Campbell, 1968, p. 384).

In summary, transformation is socially constructed, relational, and linked with the co-construction of knowledge. Transformation of the individual and the system are interconnected and simultaneously coeffective. Furthermore, transformation requires some degree of relational support and guidance; it cannot transpire in isolation because of the inherent interdependence of life.

\section{Synthesis}

The following is an amalgamation of the findings of this concept analysis that determined there are seven properties fundamental to transformation (dynamism, force, movement, suspension, novelty, irreversibility, and autopoietic); three temporal properties (process, nontemporal, and personally relevant timing); and two contextual properties (social disequilibrium and psychological support). Transformation is an irreversible change in form or structure comprised of dynamism (a force producing motion), a force (creative energy, divine, consciousness, transformative experience, mind, and/or grief), movement of consciousness (bidirectional going beyond, expanding, and transcending; contracting, moving inward; as the collective attains greater consciousness) inspired by novelty (new experiences) and facilitated through suspension (liminal or altered state of introspection, chaos, and learning). Transformation requires irreversible processes that dissolve outdated structures (e.g., ego or mind) and autopoietic self-creating activities inherent to life that involve openness and experimentation and build an optimal, new, and more complex structure. Transformation requires a relational context that is supportive of, affected by, and effects upheaval occurring in social and natural systems. Transformation is experienced in relation to time as a linear unfolding or event and a nontemporal state that is propelled in part, by events occurring with personally synchronous timing.

\section{Implications}

The findings from of this study can be used in clinical practice as a lens through which to analyze the client's problems and potentials-a psychoeducation tool to help demystify frustrating aspects of transformation and normalize distressing yet necessary aspects of the experience. Clinicians can use this study for client education to reframe the chaos and suffering endemic to transformation to reveal the underlying elements that cause growth, hope, and eventually, a new self. Finally, clients might benefit from understanding transformation and adopting terms such as "flocculation", "force", and "autopoiesis", which are devoid of psychological language baggage, to describe, understand and embrace personal circumstances. 
Future research can continue to compare and contrast findings from this study with existing and emerging theory, contributing to and improving existing conceptualizations. Although this was a comprehensive analysis, the results might be missing elements or perspectives issuing increased consolidation of the properties: for example, the five types of forces reflect existing literature, but determining if and how those properties could be combined, classified and/or eliminated lay beyond this study's scope.

Additional research might distill the five forces into one primary force or specify the forces at human (i.e., grief) and universal levels (i.e., creative force), or as spiritual (i.e., God or transcendent) vs. secular/scientific (dissipative force). The discrete properties lend themselves for use in empirical analysis. Studying the presence or absence of these properties by examining individuals' lived experiences (i.e., narratives, in-depth interviews, or observations) would strengthen the literature on transformation as well. A final benefit: the properties can be further studied and refined for eventual use in testing instruments.

\section{CONCLUSION}

The purpose of this study constitutes a deviation from literature about transformation that tends to analyze experiences, processes, or outcomes of transformation. This study offers a unique contribution not only because it is a transdisciplinary analysis of transformation but also because it produced a classification of properties and conditions, indispensable qualities salient to its existence. Moreover, the classification identifies and defines terms that transcend language typically used in social sciences, thereby opening opportunities for greater communication, information sharing, and understanding of this highly complex phenomenon. Forthcoming research is poised to generate an operational definition, reveal new techniques and processes that advance psychospiritual growth, and further investigate and refine properties and conditions fundamental to transformation that remain vague and unexplored. 
Ross, S. L. (2020). A Concept Analysis of the Properties and Conditions of Transformation. Advances in Social Sciences Research Journal, 7(5) 522-544.

\section{References}

Almaas, A. H. (2000). The void: Inner spaciousness and ego structure (2nd ed.). Boston, MA: Shambhala. (Original work published 1986)

Anderson, R., \& Braud, W. (2011). Transforming self and others through research: Transpersonal research methods and skills for the human sciences and humanities. Albany: State University of New York Press.

Artigiani, R. (1987). Revolution and evolution: Applying Prigogine's dissipative structures model. Journal of Social and Biological Structures, 10(3), 249-264.

Ashby, R. (1956). Introduction to cybernetics. New York, NY: Wiley.

Assagioli, R. (1975). The resolution of conflicts and spiritual conflicts and crises. Psychosynthesis Research Foundation, 34. Retrieved from http://www.psykosyntese.dk/a-186/

Atwood, M. A. (2010). Hermetic philosophy and alchemy: A suggestive inquiry into 'the Hermetic Mystery.' New York, NY: Routledge. (Original work published YYYY)

Baker, V. (2012). The Alchemy of Change: A mixed-methods study of transformation in an online master's program in transpersonal psychology. Doctoral dissertation. Institute of Transpersonal psychology, ProQuest, 3522527.

Bouissac, P. (Ed.). (2007). Encyclopedia of Semiotics Online. Oxford, England: Oxford University Press. Retrieved from URL (subscription required)

Boyd, R. D. (1990). An approach to facilitating personal transformation in small groups. Small Group Research, 21(4), 522-537.

Boyd, R. D., \& Myers, J. G. (1988). Transformative education. International Journal of Lifelong Education, 7(4), 261-284.

Bray, P. (2013). Bereavement and transformation: A psycho-spiritual and post-traumatic growth perspective. Journal of Religious Health, 52(3), 890-903.

Bray, P. (2017). The hero-journey, Hamlet and positive psychological transformation. Journal of Humanistic Psychology, 58(5), 525-555. https://doi.org/10.1177/0022167816689357

Brinton Perera, S. (1981). Descent to the goddess: A way of initiation for women. Toronto, ON: Inner City Books.

Burckhardt, T. (1997). Alchemy: Science of the cosmos, science of the soul (Rev. ed.; W. Stoddart, Trans.). Louisville, KY: Fons Vitae. (Original work published 1960).

Campbell, J. (1968). The hero with a thousand faces (2nd ed.). Princeton, NJ: Princeton University Press.

Chandler, C. K., Holden, J. M., \& Kolander, C. A. (1992). Counseling for spiritual wellness: Theory and practice. Journal of Counseling \& Development, 71(2), 168-175.

Chilton, J. M. (2015). Transformation from within: A concept analysis of epiphany. Creative Nursing, 21(1), 15-20.

Churchill, N. (2011). Whiteshell woman: Shamanic dismemberment and transformation. Jung Journal: Culture \& Psyche, 5(1), 81-97.

Clark, W. H. (1958). The psychology of religion. New York, NY: Macmillan.

Clements, C. J. (2016). Toward a transpersonal model of psychological illness, health, and transformation. Journal of Transpersonal Psychology, 48(1), 57-87.

Coghlan, A., \& Weiler, B. (2015). Examining transformative processes in volunteer tourism. Current Issues in Tourism, 21(5), 567-582.

Dąbrowski, K. (1964). Positive disintegration. Boston, MA: Little Brown \& Co.

Dąbrowski, K. (1972). Psychoneurosis is not an illness: Neuroses and psychoneuroses from the perspective of positive disintegration. London, England: Gryf Publications.

de Grâce, G. (1974). The compatibility of anxiety and actualization. Journal of Clinical Psychology, 30(4), 566-568.

Downton, J. V. (1989). Individuation and shamanism. Journal of Analytical Psychology, 34(1), 73-88. 
Dynamic. (2019). Lexico.com. Retrieved from https://www.lexico.com/en/definition/dynamic Dynamism. (2019). Lexico.com. Retrieved from https://www.lexico.com/en/definition/dynamism

Eliade, M. (2005). Rites and symbols of initiation: The mysteries of birth and rebirth (W. R. Trask, Trans.). Putnam, CT: Spring. (Original work published 1958)

Fisher, D., \& Torbert, W. (1995). Personal and organizational transformations: The true challenge of continual quality improvement. London, England: McGraw Hill.

Freedman, N. (1985). The concept of transformation in psychoanalysis. Psychoanalytic Psychology, 2(4), 317-339.

Form. (2019). Lexico.com. Retrieved from https://www.lexico.com/en/definition/form

Gebser, J. (1991). The ever-present origin (N. Barstad \& A. Mickunas, Trans.), Athens: Ohio University Press. (Original work published 1949)

Genmill, G., \& Smith, C. (1985). A dissipative structure model of organization transformation. Human Relations, 38(8), 751-766.

Gonzáles, J. M. (2010). Seemingly spontaneous experience of transformation and its precursors (Doctoral dissertation). Retrieved from ProQuest Dissertations and Theses database (Dissertation No. 3404201)

Grof, S., \& Grof, C. (Eds.). (1989). Spiritual emergency: When personal transformation becomes a crisis. New York, NY: G. P. Putnam's Sons.

Gunn, R. J. (2000). Journey into emptiness: Dōgen, Merton, Jung, and the quest for transformation. Mahwah, NJ: Paulist Press.

Hall, J. A. (1984). Dreams and transference/countertransference: The transformative field. Chiron, 31-51.

Hart, T. (2000). Transformation as process and paradox. The Journal of Transpersonal Psychology, 32(2), 157-164.

Hefferon, K., Grealy, M., \& Mutrie, N. (2009). Transforming from cocoon to butterfly: The potential role of the body in the process of posttraumatic growth. The Journal of Humanistic Psychology, 50(2), 224-247.

Henderson, R. (1995). Outdoor travel: Explorations for change (Unpublished doctoral dissertation). University of Alberta, Edmonton, Alberta.

James, W. (2004). The varieties of religious experience: A study in human nature. New York, NY: Touchstone Books. (Original work published 1902)

Jung, C. G. (1966a). Principles of practical psychotherapy (G. Adler \& R. F. C. Hull, Trans.). In G. Adler \& R. F. C. Hull (Eds.), The collected works of C. G. Jung, Vol. 16: Practice of Psychotherapy (2nd ed., pp. 3-20). Princeton, NJ: Princeton University Press. (Original work published 1935)

Jung, C. G. (1966b). The psychology of the transference (G. Adler \& R. F. C. Hull, Trans.). IIn G. Adler \& R. F. C. Hull (Eds.), The collected works of C. G. Jung, Vol. 16: Practice of Psychotherapy (2nd ed., pp. 163-323). Princeton, NJ: Princeton University Press. (Original work published 1946)

Jung, C. G. (1970). The collected works of C. G. Jung, Vol. 14: Mysterium coniunctionis (G. Adler \& R. F. C. Hull, Trans. \& Eds., 2nd ed.). Princeton, NJ: Princeton University Press. (Original work published 1955-1956)

Jung, C. G. (1983). The collected works of C. G. Jung, Vol. 13: Alchemical studies (G. Adler \& R. F. C. Hull, Trans. \& Eds., 2nd ed.). Princeton, NJ: Princeton University Press. (Original work published 1967)

Jung, C. G. (1988). Jung's Seminar on Nietzsche's Zarathustra: Notes of the seminar given in 1934-1939 (Vols. 1-2, J. L. Jarrett, Ed.). Princeton, NJ: Princeton University Press. (Original work delivered 1934-1939)

Jung, C. G. (2011). Synchronicity: An acausal connecting principle (R. F. C. Hull, Trans.). Princeton, NJ: Princeton University Press.

Kegan, R. (2000). What "form" transforms? A constructive-developmental approach to transformative learning. In J. Mezirow \& Associates (Eds.), Learning as transformation: Critical perspectives on a theory in progress (pp. 35-70). San Francisco: Jossey-Bass. 
Ross, S. L. (2020). A Concept Analysis of the Properties and Conditions of Transformation. Advances in Social Sciences Research Journal, 7(5) 522-544.

Kinneavy, J., \& Eskin, C. (2000). Kairos in Aristotle's rhetoric. Written Communications, 17(3), 432-444.

Kioukova, Z. (2016). The embodied experience of transformation during relational somatic psychotherapy: $A$ phenomenological study from the clients' perspective (Doctoral dissertation). Retrieved from ProQuest Dissertations and Theses database (Dissertation No. 10255841)

Kottler, J. A. (1998). Transformative travel. The Futurist, 32(3), 24-29.

Laksi, M. (1961). Ecstasy: A study of some secular and religious experiences. London, England: The Cresset Press.

László, E. (1978). The inner limits of mankind. New York, NY: Pergamon Press.

Lean, G. L. (2009) Transformative travel inspiring sustainability. In R. Bushell \& P. J. Sheldon (Eds.), Wellness and tourism: mind, body, spirit, place. Innovation and tourism connecting theory and practice (pp. 89-102). New York, NY: Cognizant Communication.

Leffel, G. M. (2011). Beyond meaning: Spiritual transformation in the paradigm of moral intuitionism-A new direction for the psychology of spiritual transformation. Part 2: Three cognitive systems of spiritual transformation: A moral intuitionist model. In R. L. Piedmont \& A. Village (Eds.), Research in the Social Scientific Study of Religion (Vol. 22, pp. 77-125). Boston, MA: Brill.

Leicester, H. M., \& Klickstein, H. S. (1952). A source book in chemistry, 1400-1900. Cambridge, MA: Harvard University Press.

Levine, P. A. (1976). Accumulated stress, reserve capacity and disease (Doctoral dissertation). Retrieved from ProQuest Dissertations and Theses database (Dissertation No. 7715760)

Levine, P. A. (2010). In an unspoken voice: How the body releases trauma and restores goodness. Berkeley, CA: North Atlantic Books.

Levitt, H. M., Frankel, Z., Hiestand, K., Ware, K., Bretz, K., Kelly, R., ... Raina, K. (2004). The transformational experience of insight: A life-changing event. The Journal of General Evolution, 58(1), 33-43.

Lewin, K., \& Cartwright, D. (Eds.). (1951). Field theory in social science. New York, NY: Harper.

Lichtenstein, B. M. (1997). Grace, magic, and miracles: A "chaotic" logic of organizational transformation. Journal of Organizational Change Management, 10(5), 393-411.

Lincoln, B. (1981). Emerging from the chrysalis: Rituals of women's initiation. New York, NY: Oxford University Press.

Lindstrom, S. K. (2011). Travel and adult transformative learning (Doctoral dissertation). Retrieved from ProQuest Dissertations and Theses database (Dissertation No. 3450553)

Loder, J. E. (1989). The transforming moment. Colorado Springs, CO: Helmers and Howard.

Loevinger, J. (1976). Ego development. San Francisco, CA: Jossey-Bass.

Loye, D. \& Eisler, R. (1987). Chaos and transformation: Implications of nonequilibrium theory for social science and society. Behavioral Science, 32(1), 53-61.

Ludwig, A. M. (1969). Altered states of consciousness. In C. Tart (Ed.), Altered states of consciousness (pp. 10-25). New York, NY: Wiley.

Luke, H. M. (1984). The voice within. New York, NY: Crossroad.

Maslow, A. (1999). Towards a psychology of being (3rd ed.). New York, NY: Van Nostrand.

McDonald, M. G. (2007). The nature of epiphanic experience. The Journal of Humanistic Psychology, 48(1), 89-115.

Metamorphosis. (2019). Lexico.com. Retrieved from https://www.lexico.com/en/definition/metamorphosis

Metzner, R. (1998). The unfolding self: Varieties of transformative experiences (Rev. ed.). Novato, CA: Origin Press.

Mezirow, J. (1978). Perspective transformation. Adult Education, 28(2), 100-110.

Mezirow, J. (1991). Transformative dimensions of adult learning. San Francisco, CA: Jossey-Bass. 
Mezirow, J. (1997). Transformative learning: Theory to practice. New Directions for Adult and Continuing Education, 74, 5-12. https://doi.org/10.1002/ace.7401

Mezirow, J. (2000). Learning as transformation: Critical perspectives on a theory in progress. San Francisco, CA: JosseyBass.

Mezirow, J., \& Taylor, E. W., \& Associates. (2009). Transformative learning in practice: Insights from community, workplace, and higher education. San Francisco, CA: Jossey-Bass.

Moore, R. L. (2001). The archetype of initiation: Sacred space, ritual process, and personal transformation. Philadelphia, PA: Xlibris.

Mustonen, P. (2006) Volunteer tourism: Postmodern pilgrimage. Journal of Tourism and Cultural Change, 3(3), 160177.

Neal, J. A., Lichtenstein, B. M. B., \& Banner, D. (1999). Spiritual perspectives on individual, organizational, and societal transformation. Journal of Organizational Change Management, 12(3), 175-186.

Newman, M. A. (1978, December). Toward a theory of health. Paper presented at the second annual Nurse Educator Conference, New York, NY.

Novelty. (2019). Lexico.com. Retrieved from https://www.lexico.com/en/definition/novelty

Nuopponen, A. (2010a). Methods of concept analysis-A comparative study, part 1 of 3. The LSP Journal, 1(1), 4-12. Available from http://rauli.cbs.dk/index.php/lspcog/index

Nuopponen, A. (2010b). Methods of concept analysis-Towards systematic concept analysis, part 2 of 3. The LSP Journal, 1(1), 5-14. Available from http://rauli.cbs.dk/index.php/lspcog/index

Olsen, C. (1992). A philosophical inquiry into the alchemy of light and dark in the nuptial union of Sanjuanist spirituality (Master's thesis). Retrieved from ProQuest Dissertations and Theses database (Thesis No. 1347870)

Ouspensky, P. D. (2001). In search of the miraculous, the teachings of G. I. Gurdjieff: The classic exploration of Eastern religious thinking and philosophy. San Diego, CA: A Harvest Book. (Original work published 1949)

Parappully, J., Rosenbaum, R., Van den Daele, L., \& Nzewi, E. (2002). Thriving after trauma: The experience of parents of murdered children. Journal of Humanistic Psychology, 42(1), 33-70.

Perls, F. (1969). Gestalt therapy verbatim. New York, NY: Bantam Books. (Original work published 1959)

Persaud, S. M. (2000). Grace unfolding: Self-transformation as a sacred, transgressive art of listening to the inner voice. A Jungian perspective (Doctoral dissertation). Retrieved from ProQuest Dissertations and Theses database (Dissertation No. NQ66307)

Pikovsky, A., Rosenblum, M., \& Kurths, J. (2001). Synchronization: A universal concept in nonlinear sciences. New York, NY: Cambridge University Press.

Pine, B. J., \& Gillmore, J. H. (2000). The experience economy: Updated edition. Boston, MA: Harvard Business Review.

Polanyi, M. (1962). Tacit knowing: Its bearing on some problems of philosophy. Reviews of Modern Physics 34(4), 601615.

Prigogine, I. (1978). Time, structure, and fluctuations. Science (New Series), 201(4358), 777-785.

Prigogine, I. (1993). Time, structure, and fluctuations [lecture]. In T. Frängsmyr (Chief Ed.) \& S. Forsén (Ed.), Nobel Lectures, Chemistry 1971-1980 (pp. 249-252). Singapore: World Scientific Publishing. (Original lecture delivered December 8, 1977) https://www.nobelprize.org/uploads/2018/06/prigogine-lecture.pdf

Prigogine, I. (1997). The end of certainty: Time, chaos, and the new laws of nature. New York, NY: Free Press.

Prigogine, I., \& Stengers, I. (1984). Order out of chaos. New York, NY:Bantam Books.

Resonance. (2019). Lexico.com. Retrieved from https://www.lexico.com/en/definition/resonance

Rodgers, B. L., \& Knafl, K. A. (2000). Concept development in nursing, foundations, techniques, and applications (2nd ed.). Philadelphia, PA: Saunders. 
Ross, S. L. (2020). A Concept Analysis of the Properties and Conditions of Transformation. Advances in Social Sciences Research Journal, 7(5) 522-544.

Ross, S., Zammit, C., \& Zollinger, R. (2005). Living in the field of transformation. In D. Vlosa, G. Kiebaso, \& J. Radford (Eds.), Appreciating the best of what is: Envisioning what could be-Proceedings for the sixth international Transformative Learning Conference (pp. 407-412). East Lansing: Michigan State University \& Grand Rapids Community College.

Ross, S. L. (2008). The integration of transformation: A cooperative inquiry among women after transformative travel. Dissertations Abstracts International: Section B. Sciences and Engineering, 69(3).

Ross, S. L. (2010). Transformative travel: An enjoyable way to foster radical change. ReVision, 32(1), 54-61.

Ross, S. L. (2017). The making of everyday heroes: Women's experiences of transformation and integration. Journal of Humanistic Psychology, 59(4), 499-521. https://doi.org/10.1177/0022167817705773

Ross, S. L. (2019). Who put the super in superhero? Transformation and heroism as a function of evolution. Frontiers in Psychology, 9, 2514. https://doi.org/10.3389/fpsyg.2018.02514

Ross, S.L. (2020a). A concept analysis of the form that trans-forms as a result of transformation. International Journal of Psychological Studies, 12(2).

Ross, S.L. (2020b). A transdisciplinary definition of transformation using a concept analysis. Manuscript submitted for publication.

Ross, S.L. (2020c). The integration of transformation: Extending Campbell's monomyth. Heroism Science, 4(2), 1-29.

Saunders, R. E., Laing, J., \& Weiler, B. (2013). Personal transformation through long-distance walking. In S. Filep \& P. L. Pearce (Eds.), Tourist experience and fulfilment: Insights from positive psychology (pp. 127-146). New York, NY:

Routledge.

Schmidt-Lauff, S. (2012). Time as reflective moment of Bildung and transformative learning. In A. Laros, T. Fuhr, \& E. W. Taylor (Eds.), Transformative learning meets Bildung: International issues in adult education (pp. 107-116).

Rotterdam, The Netherlands: SensePublishers.

Scott, S. M. (1997). The grieving soul in the transformation. New Directions for Adult and Continuing Education, 74, 4150. https://doi.org/10.1002/ace.7405

Scott, S. M. (2003). The social construction of transformation. Journal of Transformative Education, 1(3), 264-282.

Siegel, D. J. (2016). Mind: A journey to the heart of being human. New York, NY: W. W. Norton.

Siegel, J. T. (2013). Goal disruption theory [Web page]. Retrieved from http://www.GDTheory.com

Sinetar, M. (1986). Ordinary people as monks and mystics. New York, NY: Paulist Press.

Sri Aurobindo. (1972). The Hour of God and other writings: Volume 17. Pondicherry, India: Sri Aurobindo Ashram.

Sri Aurobindo. (1990). Future evolution of man: The divine life upon earth (2nd ed., P. B. Saint-Hilaire, Comp.). Twin Lakes, WI: Lotus Press. (Original work published 1963)

Sri Aurobindo, The Mother, \& Dalal, A. S. (2002). Our many selves: Practical yogic psychology. Twin Lakes, WI: Lotus Press.

Starbuck, E. (1901). The psychology of religion. New Yorkm NY: Scribner's.

Steiner, R. (2005). Knowledge of the higher worlds: How is it achieved? (J. Davy \& D. S. Osmond, Trans.). Herndon, VA: Rudolf Steiner Press. (Original work published 1904-1905)

Stevens, S. S. (1935). The operational definition of psychological concepts. Psychological Review, 42(6), 517-527.

Suedfeld, P., \& Bluck, S. (1993). Changes in integrative complexity accompanying significant life events: Historical evidence. Journal of Personality and Social Psychology, 64(1), 124-130.

Tart, C. T. (1986). Waking up: Overcoming the obstacles to human potential. Boston, MA: Shambhala.

Takala, T., \& A.-M. Lämsä (2001). Tulkitseva käsitetutkimus organisaatio- ja johtamistutkimuksen tutkimusmetodologisena vaihtoehtona. Liiketaloudellinen aikakauskirja 50(3), 371-390. An English abstract: 
Interpretative study of concepts as a methodological alternative in the field of organization and management research. Available from http://lta.hse.fi/2001/3/lta_2001_03_s4.pdf

Taylor, S. (2012). Transformation through suffering a study of individuals who have experienced positive psychological transformation following periods of intense turmoil. Journal of Humanistic Psychology, 52(1), 30-52.

Teas, J. (1988). “I'm studying monkeys; what do you do?"-Youth travelers in Nepal. Kroeber Anthropological Society Papers, 67/68, 35-41.

Tedeschi, R. G. (1999). Violence transformed: Posttraumatic growth in survivors and their societies. Aggression and Violent Behavior, 4(3), 319-341.

Tedeschi, R., \& Calhoun, L. (1995). Trauma and transformation: Growing in the aftermath of suffering. London, England: SAGE.

Tedeschi, R. G., \& Calhoun, L. G. (2012). Pathways to personal transformation: Theoretical and empirical developments. In P. T. P. Wong (Ed.), The human quest for meaning: Theories, research, and applications (pp. 559-572). New York, NY: Routledge/Taylor \& Francis.

Tedeschi, R. G., Calhoun, L. G., \& Groleau, J. M. (2015). Clinical applications of posttraumatic growth. In S. Joseph (Ed.), Positive psychology in practice: Promoting human flourishing in work, health, education, and everyday life (2nd ed.). Hoboken, NJ: John Wiley \& Sons.

Tisdell, E. J. (2012). Themes and variations of transformational learning: Interdisciplinary perspectives on forms that transform. In E. W. Taylor \& P. Cranton (Eds.), The handbook of transformative learning: Theory, research, and practice (pp. 21-36). San Francisco, CA: Jossey-Bass.

Trans-. (2019). Lexico.com. Retrieved from https://www.lexico.com/en/definition/trans_

Transformation. (2019). Lexico.com. Retrieved from https://www.lexico.com/en/definition/transformation

Transformative. (2019). Lexico.com. Retrieved from https://www.lexico.com/en/definition/transformative

Trousdell, R. (2008). Tragedy and transformation: The Oresteia of Aeschylus. Jung Journal: Culture \& Psyche, 2(3), 538.

Turner, V. (1967). The forest of symbols: Aspects of Ndembu ritual. Ithaca, NY: Cornell University Press.

Turner, V. (1969). The ritual process: Structure and anti-structure. Ithaca, NY: Cornell University Press.

Turner, V., \& Turner, E. L. B. (1978). Image and pilgrimage in Christian culture. New York, NY: Columbia University Press.

van Gennep, A. (1960). The rites of passage: A classic study of cultural celebrations (M. B. Visedom \& G. L. Caffee, Trans.). Chicago, IL: University of Chicago Press. (Original work published 1909)

Vekilov, P. G. (2010). Nucleation. Crystal Growth and Design, 10(12), 5007-5019.

Wade, G. H. (1998). A concept analysis of personal transformation. Journal of Advanced Nursing, 28(4), 713-719.

Weiss, T. (2013). Personal transformation: Posttraumatic growth and gerotranscendence. The Journal of Humanistic Psychology, 54(2), 203-226.

White, N. R., \& White, P. B. (2004). Travel as transition: Identity and place. Annals of Tourism Research, 31(1), 200218.

Wiedemann, F. (1985). The paradox of wholeness: A critique and appreciation of transpersonal psychology. The C. G. Jung Institute Library Journal, 6(1), 1-38.

Wiethaus, U. (1996). Ecstatic transformation: Transpersonal psychology in the work of Mechthild of Magdeburg. Syracuse, NY: Syracuse University Press.

Wilber, K. (1995). Sex, ecology, spirituality: The spirit of evolution. Boston, MA: Shambhala.

Zahra, A., \& McIntosh, A. J. (2007). Volunteer tourism: Evidence of cathartic tourist experiences. Tourism Recreation Research, 32(1), 115-119. 